\title{
Optimization of welding heat regimes for glass shell construction
}

\author{
Hachkevych O. ${ }^{1,2}$, Irza E. ${ }^{1}$, Torskyy A. ${ }^{3}$, Koziarska A. ${ }^{2}$ \\ ${ }^{1}$ Pidstryhach Institute for Applied Problems of Mechanics and Mathematics \\ National Academy of Sciences of Ukraine, \\ 3-b Naukova Str., 79060, Lviv, Ukraine \\ ${ }^{2}$ Opole University of Tecnnology, \\ 76 Prószkowska Str., 45-758 Opole, Poland \\ ${ }^{3}$ Centre of Mathematical Modeling IAPMM of Ukranian National Academy of Sciences, \\ 15 Dudayev Str., 79005, Lviv, Ukraine
}

(Received 3 June 2018)

\begin{abstract}
A numerical optimization procedure of the local heat regime for a glass shell of revolution during welding is proposed. This procedure is based on the model of thermo-viscoelastic solid taking into account residual deformations and stresses, which emerge during welding.
\end{abstract}

Keywords: optimization, thermal treatment, circular shell.

2000 MSC: 74A10, 74B10

UDC: 539.3

DOI: $10.23939 / \mathrm{mmc} 2018.01 .016$

\section{Introduction}

Glass shell constructions are widely used in various branches of industry, especially when they are subjected to aggressive environment. Component parts of such constructions are various types of circular shells. It is known $[1,2]$ that technology of production of such construction includes formation of corresponding glass elements, treatment of their butt-ends, and connection two or more parts. In the paper there is proposed a methodology of calculation of local temperature regimes for glass elements, which provide formation of welding joints that are reliable and stable during exploitation of the mentioned construction in aggressive environments with temperature and power loading.

In the production of glass constructions with welding joints, they are subjected to local heat treatment by given power loading and attaching conditions. A peculiarity of such a joint formation is the necessity of heating of near-joint area of the construction to temperature of glass softening (this temperature is greater than glass temperature [2]), which provides significant alteration of temperature and physicomechanical properties of the material in the local area. Significant deformation and stresses can occur in the construction during and after production, and they can exceed of permissible ones. That is why an actual problem is to develop the optimal deformation and stresses heat regimes for welding joint of glass construction.

\section{Governing equations}

A weld is formed by heating of its narrow region to near-softening temperature, providing mechanical contact of joint elements, subsequent heating to softening temperature, exposing with such temperature and subsequent cooling to natural temperature by given technological power loading and attaching condition. At the same time, for providing attaching condition and performance assurance of the construction during heating, exposing and cooling, stresses and deformations should not exceed of permissible ones. As a rule, to provide uniform heating lessening of gravity influence, particularly to avoid arch effect during high temperature, elements of the construction are revolved. 
During heating elements of the shell are not joined with each other and are free from technological power loading. As a result, their stresses are less than in the whole shell construction with symmetric characteristics of attached elements by the same heating conditions. According to that, for the calculation of optimal welding (heat) regime that stipulates joint formation, shell construction is modeled by whole continuous shell (which consists of two joint parts). Heating (taking into account circular motion of welding) is modeled by the given local environment temperature distribution.

It is assumed that technological load, which provides attached elements into steady mechanical contact during high temperature, is short-term and insignificant and the speed of the circular motion does not stipulate inertia stresses and there are no arch effects of softening parts of the shell.

A mathematical model of quantitative description and of stress and deformation optimization of physicomechanical processes, which occur during formation of welding joint for circular glass shell elements, is formulated.

It is assumed that glass solid occupies the domain $\Omega$ of Euclidean space $\mathbb{R}^{3}$ and is bounded by the continuous surface $\Gamma$. It is given a curvilinear coordinate system $O x^{1} x^{2} x^{3}$. The glass solid is heated by an external source with the temperature $t_{c}$ through part of the surface $\Gamma_{t}$. There are distributed heat sources with the power $Q$ in the solid. The maximal temperature of heated solid is $t^{*}$ (about $900^{\circ} \mathrm{C}$ ). Then the solid is cooled by external environment with temperature $t_{c}$ to the level of the maximal temperature $t_{k}$. For the part $\Gamma_{u}$ of the surface $\Gamma$, there is given the displacement $\boldsymbol{u}=\left(u_{1}^{0}, u_{2}^{0}, u_{3}^{0}\right)$, and in the part $\Gamma_{\sigma}$ there is given the power loading, which is characterized by vector $\boldsymbol{p}=\left(p^{1}, p^{2}, p^{3}\right),\left(\Gamma_{u} \cup \Gamma_{\sigma}=\Gamma\right)$.

The problem is formulated in quasi-static formulation and in terms of displacements (taking into account the dependence of heat physical glass parameters on temperature).

According to the assumption, the temperature distribution in the solid is described by the temperature equation [1]:

$$
\rho c \frac{\partial t}{\partial \tau}=\nabla(\lambda \nabla t)+Q
$$

with following boundary and initial conditions:

$$
\left[\lambda \frac{\partial t}{\partial n}+\alpha\left(t-t_{c}\right)\right]_{\Gamma_{t}}=0 ; \quad t(M, 0)=t_{0} .
$$

Because of maximal heat temperature is about $900^{\circ} \mathrm{C}$, the coefficient of linear heat expansion $\alpha$ can take into account the emanation heat exchange with external environment [1].

For quantitative description of stress-strained state of glass solid stipulated by heat loading, we can use the equation [1], where the increment of the component of whole deformation tensor is as follows:

$$
d \varepsilon_{i j}=d \varepsilon_{i j}^{e}+d \varepsilon_{i j}^{t}+d \varepsilon_{i j}^{c}+d \varepsilon_{i j}^{o s t} .
$$

Where: $d \varepsilon_{i j}^{e}=\frac{1}{2 G} d S_{i j}+\frac{1}{9 K} g_{i j} d \sigma$ is the increment of elastic deformation tensor; $d \varepsilon_{i j}^{t}=\alpha_{t} g_{i j} d t$ is the increment of temperature deformation tensor; $d \varepsilon_{i j}^{c}=\frac{1}{2 G \eta} S_{i j} d \tau$ is the increment of viscosity deformation tensor; $d \varepsilon_{i j}^{o s t}=-\alpha_{t} g_{i j} d \Phi$ is the increment of residual deformation tensor during reaching glass temperature $t_{g}$.

In addition to the equations (1)-(3), in the domain $\bar{\Omega}$ should be satisfied the equilibrium equations:

$$
\nabla_{j} \sigma^{i j}+F^{i}=0
$$

and the mechanical boundary conditions:

$$
\left(n_{j} \sigma^{i j}-p^{i}\right)_{\Gamma_{\sigma}}=0 ; \quad u_{i / \Gamma_{u}}=u_{i}^{0} \quad(i=1, \ldots, 3) .
$$

It is considered the case of small deformation and assumed linear relation between the deformation tensor $\hat{\varepsilon}$ and the displacement vector $\boldsymbol{u}=\left(u_{1}, u_{2}, u_{3}\right)$ 


$$
\varepsilon_{i j}=\frac{1}{2}\left(\nabla_{i} u_{j}+\nabla_{j} u_{i}\right)
$$

The equations (1)-(6) form a complete system for determining the temperature field, the displacement vector, the deformation and stress tensors by given environment temperature $t_{c}$, the power of internal heat sources $Q$ and external loading $\boldsymbol{p}$.

\section{The optimization problem}

A stress and deformation optimization problem of temperature regimes (heating and cooling) of the solid by given mechanical conditions is considered.

During heating from the initial temperature $t_{0}$ to the maximal temperature $t^{*}$, the control function is the temperature of external environment $t_{c}$ (it is defined: $h$ ), the power of the internal heat source $Q$ is given.

The chosen control function $h$ complies with following conditions:

$$
h \in\left\{S_{1}\right\}: \forall h \in\left\{S_{1}\right\}, \quad \exists \tau^{*} \in[0, \tau], \quad \max t\left(M, \tau^{*}\right)=t^{*}, \quad M \in \bar{\Omega},
$$

by given the limits on temperature, stress and deformation:

$$
\begin{gathered}
t_{0} \leqslant t(M, \tau) \leqslant t^{*} ; \quad \max \sigma_{i}(M, \tau) \leqslant \sigma_{d} ; \quad \max \varepsilon_{i} \leqslant \varepsilon_{d} \\
M \in \bar{\Omega}, \quad \tau \in\left[0, \tau^{*}\right], \quad i=1, \ldots, 3 .
\end{gathered}
$$

Where: $\sigma_{i}, \varepsilon_{i}$ are the main value of tensor of normal stresses and deformation; $\sigma_{d}, \varepsilon_{d}$ are the permissible value of stresses and deformation; $S_{1}$ is the aggregate of functions, where solution is defined.

The optimum criteria is minimal heating period to the temperature $t^{*}$, which can be written as follows:

$$
I=\min \tau^{*} .
$$

The conditions (7)-(9) have such physical interpretation. During heating there is some optimal influence on the glass solid. This influence provides the minimal heating period $\tau^{*}$, when at least one point of the solid reaches the maximal temperature $t^{*}$; and stresses and deformation do not exceed permissible value.

During cooling from the stage with the maximal temperature $t^{*}$ till stage with the maximal temperature $t_{k}$, the control function $h$ should satisfy the following condition:

$$
h \in\left\{S_{2}\right\}: \forall h \in\left\{S_{2}\right\}, \quad \exists \tau_{k} \in[0, \tau], \quad \max t\left(M, \tau_{k}\right)=t_{k}, \quad M \in \bar{\Omega} .
$$

Where: $S_{2}$ is the aggregate of functions, where solution is defined.

At the same time, the conditions (8) should be satisfied. For optimum criteria is chosen minimum of the functional:

$$
I=\min F\left(\sigma_{i}^{\text {ost }}, \sigma_{0}\right),
$$

where $F$ is the functional, which defines deflection of components of stress deformation tensor from the given values of residual stresses $\sigma_{0} ; \sigma_{i}^{\text {ost }}$ is the main values of tensor of residual stresses which are stipulated by residual "freezing" deformations in the moment of glass temperature.

In this case, stress optimization of local heat regimes of glass solids is based on minimization of the functionals (9), (11) due to choosing of the control function $h$, with the conditions (7), (8), (10) and limits (1)-(6). 


\section{Metohodology of solving of direct problem}

The main point of our optimization scheme is a solution of the direct problem, which includes solving heat conductivity and thermo-viscoelastic problems. Since geometrical configuration of the domain, which is occupied by the solid, is often complicated enough, it is used weight discrepancy method in accordance with finite elements approach [3], which allows obtaining an approximate solution for the stated problems.

The equations (1)-(6) are subjected to space and time discretization. As a result, it is obtained a nonlinear algebraic equation system, which can be written as follows [3]:

$$
\left[K_{T}\right]\{T\}=\left\{F_{T}\right\}, \quad\left[K_{U, T}\right]\{U\}=\left\{F_{U, T}\right\} .
$$

Where $\left[K_{T}\right],\left[K_{U, T}\right]$ are corresponding rigidity matrixes; $\left\{F_{T}\right\},\left\{F_{U, T}\right\}$ are loading vectors [3].

In general case, the system of algebraic equation (12) is not linear and can be solved by means of an appropriate iteration method.

\section{Methodology of solving of the optimization problem}

Solving of the stated above extremal problem is defined on the base of stage parametric optimization [4]. In this case, the minimization of the functionals $(9),(11)$ is reduced to nonlinear programming problem for determining of the corresponding functions $J=J\left(h_{1}, \ldots, h_{n}\right)$, with arguments of the control function $h_{i}$ in the discrete time moments $\tau_{i}$ [4]. Therefore, the stress optimization of heating regimes of circular shells is reduced to a conditional extreme problem of the function $J$ with the limits (12) and the conditions (7), (8), (10). For solving this problem it is used Hooke-Jeeves direct search method [4].

The proposed mathematical optimization model can be used to establish optimal welding regimes of thin glass circular shells.

\section{Optimization of welding regimes for glass semi-spheres}

The described above methodology is used for the establishment of optimal welding regimes of glass semi-spheres, made of glass C-93. For the initial approach it is accepted the existent in nowadays glass production welding regime [1].

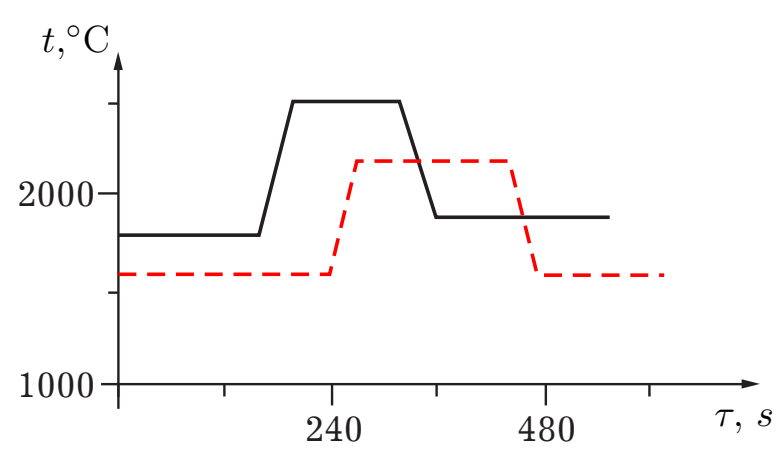

Fig. 1.

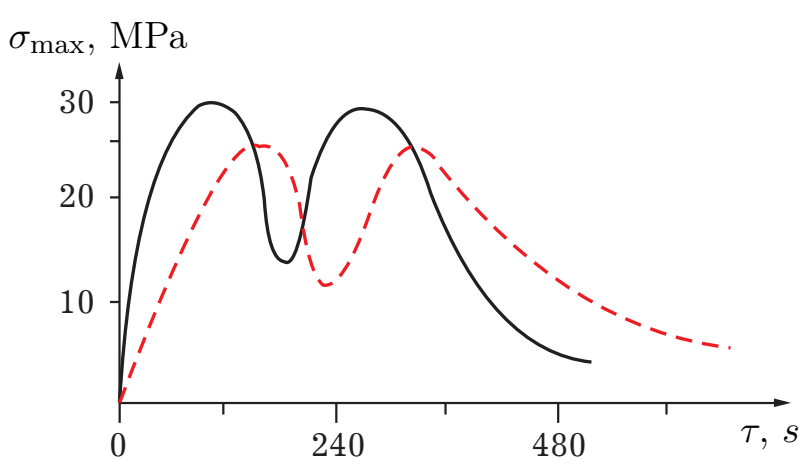

Fig. 2.

In Fig. 1 the dashed curves correspond to the initial approach of the control function $t_{c}$, and the continuous curves correspond to the optimal solution. Fig. 5 presents alteration of maximal stretch stresses along the whole length of welding process. The analysis of obtained result shows that duration of welding process under the stated by us optimal regime can be lessen about $25 \%$ in comparison with the initial one. This optimal regime provides a given level of residual stresses $(75 \mathrm{MPa})$ and complies with the given conditions. 


\title{
7. Conclusions
}

The proposed numerical methodology for the establishment of optimal regimes in terms of deformations and stress for local heating of glass elements of circular shell constructions is proposed. It provides a proper welding joint, gives a possibility to solve wide range of similar problems. This methodology can be used to various compound shells for definitions of parameters, which characterize optimal heat regimes with various heat and mechanical restrictions.

[1] BudzS. F., Irza E. M. Determination of the residual stresses in the welded joints of glass structures. J. Math. Sci. 86 (2), 2633-2636 (1997).

[2] Hachkevych O., Hachkevych M., Irza Ye., Trishch B., Kaspers'kyy Z. Metodyka rozrakhunku rezhymiv hartuvannya sklyanykh elementiv mashyn i konstruktsiy. Mashynoznavstvo. 2, 3-6 (2002).

[3] Zienkiewicz O. C., Morgan K. Finite Elements and Approximation. John Wiley \& Sons, Inc., New York (1983).

[4] Himmelblau D. M. Applied nonlinear programming. New York, McGraw-Hill (1972).

\section{Оптимізація теплових режимів зварювання оболонкових конструкцій зі скла}

\author{
Гачкевич O. ${ }^{1,2}$, Ірза . $^{1}$, Торський А. ${ }^{3}$, Козярска А. ${ }^{2}$ \\ ${ }^{1}$ Інститут прикладних проблем механіки і математики \\ ім. Я. С. Підстригача НАН Украӥни, \\ вул. Наукова, 3-б, 79060, Львів, Україна \\ ${ }^{2}$ Політехніка Опольска, \\ вул. Прушковсъка, 76, 45-758 Ополе, Польща \\ ${ }^{3}$ Центр математичного моделювання \\ Інституту прикладних проблем механіки і математики \\ ім. Я. С. Підстригача НАН Украӥни, \\ вул. Д. Дудаєва, 15, 79005, Львів, Украӥна
}

\begin{abstract}
Запропоновано чисельну методику оптимізації параметрів режиму локального нагрівання оболонок обертання зі скла під час зварювання. Методику побудовано на моделі термов'язкопружного тіла з урахуванням залишкових деформацій і напружень, які формуються під час зварювання.
\end{abstract}

Ключові слова: оптимізачіл, термічна обробка, оболонка обертання.

2000 MSC: 74A10, 74B10

удк: 539.3 